\title{
NOTAS SOBRE LA COLUMNA ABALAUSTRADA EN MÉXICO
}

\section{Por Santiago Sebastián}

El ambiente humanístico de México durante el siglo xvi se manifestó hasta en los detalles insignificantes de la decoración. Esa vuelta a la Antigüedad que entrañaba el Renacimiento aparece en las Ordenanzas de pintores y decoradores, aprobadas por el virrey don Luis de Velasco, el 4 de agosto de 1557. En ellas se dice que los pintores serían examinados de su conocimiento de lo Romano, ${ }^{1}$ es decir, del arte del Renacimiento, que era una evocación del antiguo de Roma, según la mentalidad de la época. Lo que más nos interesa es el énfasis que se daba a la pintura decorativa, y se precisaba el conocimiento no sólo de la perspectiva sino de los grutescos, que tal poder evocador de lo antiguo tuvieron para el hombre del siglo xvi. Este conocimiento o imitación del supuesto vocabulario antiguo, que significaban los grutescos, era un fenómeno similar al que se planteó con el Renacimiento literario en Europa. ${ }^{2} \mathrm{Si}$ las ordenanzas aludidas prescribían el conocimiento del repertorio decorativo del Renacimiento, cabe pensar que los artistas buscaran con interés las fuentes grabadas donde aparecieran, principalmente estampas y libros ilustrados. Por medio de estos vehículos el repertorio decorativo del llamado arte renacentista llegaba a conocimiento de los artistas mexicanos, canteros, escultores, pintores, etcétera.

Ahora, al intentar este pequeño estudio sobre la columna abalaustrada en México del siglo xvi, he conseguido la identificación de algunos grutescos y de los soportes pictóricos que hay en la famosa escalera de Actopan. Ello ha venido a sugerir que un estudio sistemático de las decoraciones grabadas que hay en los libros impresos durante los siglos Xv y xvi sería muy beneficioso para establecer la filiación no sólo de los conjuntos pictóricos sino también de algunos de los elementos ornamentales empleados en la arquitectura del siglo xvI, y aun posteriormente.

En este estudio de los modelos de columna abalaustrada que hay en México, prescindo de los magníficos ejemplares de Huejotzingo, cuyo origen parece un tanto enigmático. El soporte abalaustrado que vamos a estudiar suele tener la parte inferior del fuste en forma cilíndrica,

1 B. Lorenzot: El trabajo en México... Ordenanzas de gremios 19-22. Cfr. G. Kubler: Mexican architecture of the xvi Century II, 364. New Haven, 1948.

2 H. Gmelin: "Das Prinzip der Imitatio in den romanischen Literaturen der Renaissance" en Romanische Forschungen XLVI, 1932. F. Ulivi: L'imitazione nella poetica del Rinascimento. Milán, 1959. 
mas el resto aparece constituido por una adición de elementos bulbosos, que están separados por medio de astrágalos. Obvio es que no tratamos de todos los ejemplares conocidos sino de los más significativos.

En primer lugar tienen que considerarse las columnas de la portada del convento agustino de Acolman, que por la inscripción de una cartela sabemos que se terminó en 1560. Las columnas abalaustradas del primer cuerpo son muy interesantes. Ya indicó Toussaint la relación que ciertos detalles decorativos presentan con la sacristía mayor de la catedral de Sevilla, lo que vendría a corroborar el origen español del artista que la hizo, quien, antes de embarcarse, debió de permanecer algún tiempo en Sevilla, capital que centralizaba entonces el tráfico con las Indias. ${ }^{3}$

No conocemos un modelo español que se pueda indicar como claro precedente del tipo de columna abalaustrada que creó el maestro de Acolman. La obra parece formada con sugestiones tomadas aquí y allá. Los niños de la parte inferior parecen inspirados en un retablo, ${ }^{4}$ y precisamente Vasco de la Zarza colocó dos niños en posición ligeramente diferente en el retablo de Santa Catalina, en el crucero de la catedral de Ávila (c. 1520), y si bien el resto del fuste es diferente, ambos soportes muestran el capitel adornado con la cabeza de un animal cornudo. El fuste abalaustrado guarda cierta semejanza con los soportes gigantes de la portada de Santa María de Calatayud. 5 Pienso que esta semejanza no se deba a que el artista haya conocido el ejemplo calagurritano, sino a que ambos quizá dependan de una fuente francesa, ya que algunos detalles de la portada de Calatayud muestran relación con lo francés. Si bien las fechas que conocemos de fuentes grabadas en Francia son posteriores a la terminación de la portada de Santa María (1528), ello no invalida su dependencia de lo francés. En ilustraciones galas como la portada del libro de Livius: Le premier volume des grâs decades (Paris 1530), grabada por Galliot Du Pré, y que fue copiada un año más tarde en la obra de Jacques de Guyse: Le premier volume des Illustrations de la Gaulle belgique, así como la portada del libro de Hélisenne de Crenne: Les angoisses douloureuses (Paris 1538), grabada por Denys Janot, copiada a su vez en Les fables de Esopo (Paris 1542), hay que ver ciertos modelos de soportes abalaustrados que pudieran haber influido sobre el maestro de la portada de Acolman.

3 D. Angulo: Historia del arte hispanoamericano I, 349. Señaló otros detalles dependientes de la Capilla Real de Sevilla.

4 Angulo: Ob., cit. I, 351.

5 J. A. Baird: The churches of Mexico 1530-1800, 82, fig. 28. University of California Press. Berkeley y Los Ángeles, 1962. 


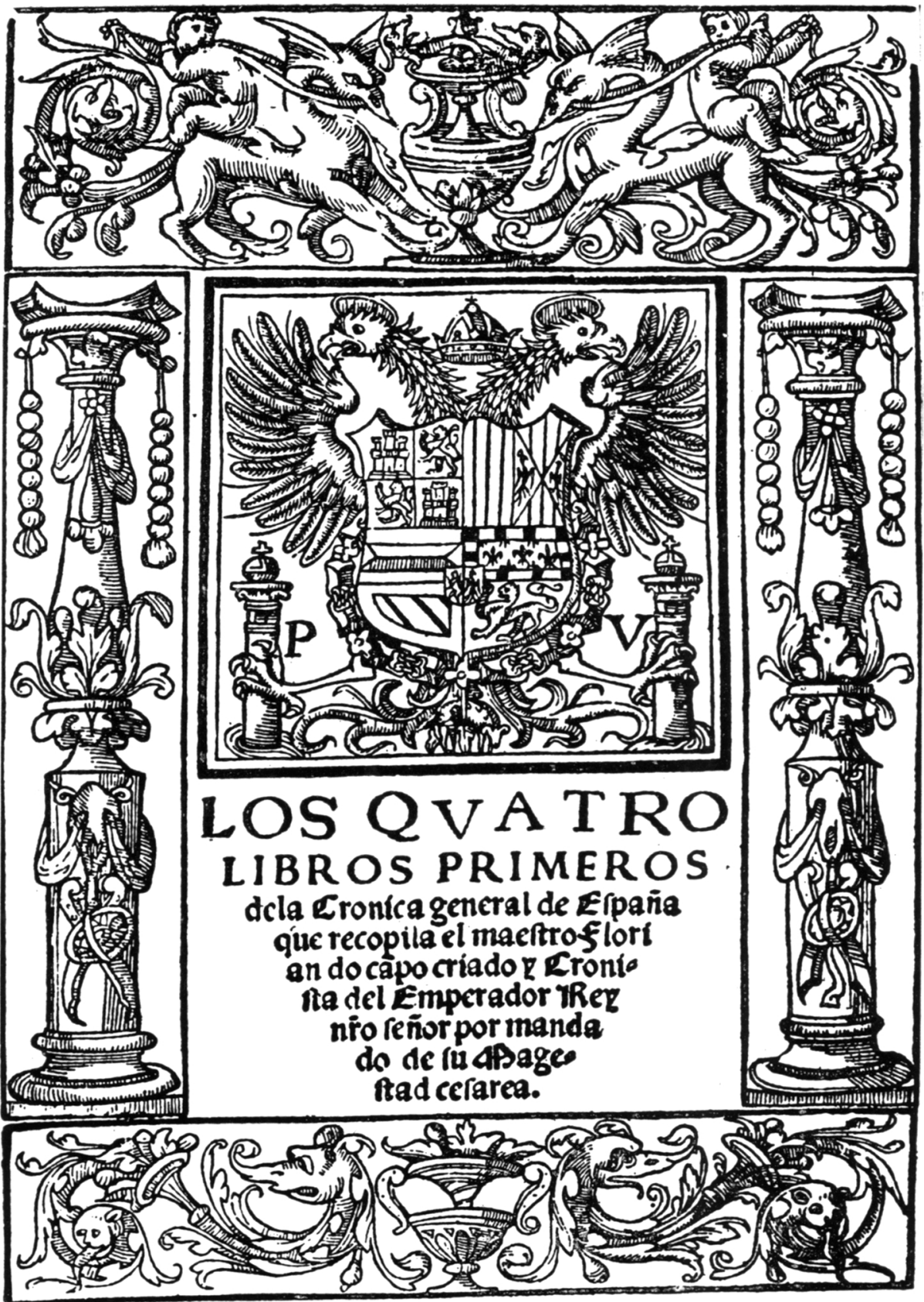

Portada de Los cuatro libros primeros de la crónica general de España, de Florián de Ocampo. 
La portada de Yuririapúndaro (c. 1566), tan ligáda a la de Acolman, ofrece en sus soportes novedades mínimas, así que no merece comentario especial. Otro tanto puede decirse de las columnas del primero y segundo cuerpos de la portada de Cuitzeo, emparentadas con los ejemplares de Acolman. Dentro del mismo círculo están las que flanquean la ventana de la portada de la iglesia de Actopan y las colosales de la portada lateral de la iglesia de Yanhuitlán.

Otro tipo de columna abalaustrada, no tan complicada como las anteriores, es el que aparece en las decoraciones murales de la escalera de Actopan. Empezado el convento a mediados del siglo xvi, quizá los frescos citados daten de un decenio más tarde. Bien evidente era que la influencia de estampas y grabados fue decisiva en la elaboración de aquel conjunto. Toussaint vio la influencia de un grabado publicado por Espinosa en 1569, ${ }^{6}$ aunque el profesor Kubler observó que el mismo grabado fue publicado ocho años antes por el mismo Espinosa, ${ }^{7}$ lo que. contribuye a precisar la fecha del conjunto pictórico.

Acabo de encontrar un modelo grabado que es decisivo para explicar el origen del entramado arquitectónico de los frescos de la escalera de Actopan y las series de grutescos que aparecen en las arquerías pictóricas. El modelo más antiguo que he hallado es la portada de la obra de Florián de Ocampo: Los cuatro libros primeros de la crónica general de España (Zamora, Agustín de Paz y Juan Picardo, c. 1542). ${ }^{8}$ El autor de dicha obra estudió en Salamanca bajo Antonio de Nebrija, y fue nombrado en 1539 cronista de Carlos V. Que la obra pasase pronto a una biblioteca americana se explicaría quizá por tener un capítulo dedicado a los descubrimientos del Caribe. ${ }^{9}$ Otro libro de la época reprodujo casi todos los elementos de la misma portada, me refiero a la Chronographia de Jerónimo de Chaves, que lleva el año de 1543. Se publicó en Sevilla en 1561 y 1566.10

Al cotejar los frescos de la arquería pictórica superior con la portada aludida se ve que la franja inferior de la arquería fue tomada de la parte superior de la portada del libro, salvo el cambio del búcaro por

6 M. Toussaint: La pintura en México durante el siglo xvi, 24, figs. 16 y 17. Enciclopedia ilustrada mexicana. México, 1936.

7 G. Kubler: Ob. cit., II, 374.

8 Reproducido por J. P. R. Lyell: Early book illustration in Spain fig. 191. Ed. Grafton. London 1926. La edición de 1543 que he consultado en la Beinecke Library (New Haven) no tiene la misma portada. Desconozco si las ediciones de 1553, 1578 y 1791 reproducen la portada primitiva.

9 H. Harrisse: Bibliotheca Americana Vetustissima, 388. Ed. P. Philes, New York, 1866.

$10 \mathrm{~J}$. Domínguez Bordona y J. Ainaud: Grabado y encuadernación, fig. 380. Ars Hispaniae xvir. Ed. Plus Ultra. Madrid, 1962. 
un escudo, pero lo demás permanece igual. La parte inferior de la portada del libro de Florián de Ocampo fue imitada en la franja superior ce la citada arquería. Las columnas pictóricas de esta arquería son las mismas que hay en la dicha portada del libro. Este tipo de soporte presenta aproximadamente un tercio del fuste en forma cilíndrica, luego viene un astrágalo y la parte superior se corona con un sencillo balaustre, decorado con guirnaldas. Este modelo fue uno de los más repetidos en las ilustraciones librescas. Aparece en forma sencilla en la portada de la obra de Nola: Libro de cozina (Toledo, 1525), y más complicado en el libro de Fernández de Oviedo: De la Natural Hystoria de las Indias (1535). De nuevo hay que anotar la semejanza de estos soportes grabados con sus similares franceses. Columnas abalaustradas parecidas hay en el libro de Gratien du Pont: Les controuerses des sexes masculin et femenin (Toulouse, 1534). Un año más tarde apareció la más bella estampa de un soporte plateresco en una escena cortesana de Francisco I, que aparece en la obra de Diodorus Siculus: Les Troys premiers livres del'histoire (Paris 1535), grabado probablemente por Le Hulin Tory. Todavía en 1551 se decoraban portadas de libros con diseños de soportes abalaustrados como la obra de Nicole Gilles. ${ }^{11}$

De las anteriores consideraciones se deduce que las supuestas columnas platerescas de México tienen un origen diferente de las que vemos en el Protorrenacimiento francés o español; tanto en Francia como en España el soporte abalaustrado apareció antes en la arquitectura que en las ilustraciones de libros, aunque en su origen haya estado motivado por estam pas o dibujos procedentes de Italia. Por lo que respecta a México hay que tener muy presente la influencia de las ilustraciones de libros pues las decoraciones platerescas se desarrollaron con posterioridad al movimiento estilístico europeo y los artífices pudieron aprovechar, como hemos visto en el caso concreto de Actopan, los grabados de libros que no existían en los inicios del Protorrenacimiento, estilo que dio tanto énfasis a lo decorativo.

\section{Universidad de Yale}

11 Reproducido en French 16th Century Books vol. I, núm. 192, 213 y 247. Cambridge, Mass, 1964.

Nota: Quedo muy reconocido al profesor Kubler por sus sugerencias e informaciones bibliográficas. 